\title{
¿ES ACASO EL BIEN COMÚN UN CONJUNTO DE CONDICIONES?
}

\author{
Is the common good a set of conditions?
}

Il bene comune è un insieme di condizioni?

Sergio Raúl Castaño ${ }^{1}$

DOI: $10.46553 /$ prudentia.89.2020.p25-47

Recibido: 11 de noviembre de 2019

Aprobado: 6 de diciembre de 2019

Resumen: La tesis que identifica el bien común con un "conjunto de condiciones" es frecuente entre los autores (y las teorías) clásicos y cristianos. Sin embargo, esta definición, en las dos formas que a menudo adopta (en sí misma: como el conjunto de condiciones necesarias para el desarrollo de la persona humana; y también como la idea de que el fin político consiste en la defensa y promoción de bienes y derechos particulares), disuena con el concepto clásico del bien común -y con la realidad misma-, porque subordina la sociedad (mejor dicho: su bien común) a los bienes particulares y suscita toda una serie de aporías, ontológicas y prácticas. La clave para una respuesta satisfactoria al problema reside en la distinción entre los fines "qui", "quo" y "cui" tal como se plantea en la obra de Louis Lachance y en la de varios de los autores de la escuela argentina del Derecho Natural.

Palabras clave: Bien común; Conjunto de condiciones; Comunidad política; Tomismo; Aristotelismo; Liberalismo.

Abstract: The thesis that defines common good as a "set of conditions" is quite common among authors and theories that consider themselves as classical. Nevertheless, this definition, in its two most common forms (as

1 Investigador principal del CONICET, Profesor titular de Teoría del Estado de la Facultad de Derecho y Ciencias Sociales de la Universidad Nacional del Comahue, Neuquén, Argentina. Director del Centro de Estudios Políticos, Universidad del Norte Santo Tomás de Aquino, Tucumán, Argentina. Correo electrónico: sergioraulcastano@gmail.com. 
the set of necessary conditions for the development of human person and as the identification of political end with the promotion of particular goods and rights), collides with the classical concept of common good, and with the reality itself, because it subordinates society (better said: the common good) to its parts and gives rise to a whole range of ontological and practical aporia. The key to a correct answer to the problem is the distinction between the end "qui", "quo" and "cui" as presented in the work of Louis Lachance and among several authors of the Argentine school of natural law.

Keywords: Common Good; Set of Conditions; Political Community; Thomism; Aristotelianism; Liberalism.

Sommario: La tesi che identifica il bene comune con un "insieme di condizioni" è prevalente tra autori (e teorie) classici e cristiani. Tuttavia, questa definizione, nelle due forme che spesso assume (di per sé: come l'insieme delle condizioni necessarie per lo sviluppo della persona umana; e anche come l'idea che il fine politico consista nella difesa e nella promozione di beni e diritti privati), si dissocia con il concetto classico del bene comune -e con la realtà stessa-, perché subordina la società (o meglio, il suo bene comune) ai beni privati e suscita un'intera serie di aporie, ontologiche e pratiche. La chiave per una risposta soddisfacente al problema è nella distinzione tra $\mathrm{i}$ fini "qui", "quo" e "cui" come è affermato nell'opera di Louis Lachance e in quello di alcuni autori della Scuola di Giurisprudenza argentina Naturale.

Parole chiave: Bene comune; Insieme di condizioni; Comunità politica; Tomismo; Aristotelismo; Liberalismo.

Para citar este artículo:

Castaño, S.R. (2020). “Es acaso el bien común un conjunto de condiciones?”. Prudentia Iuris, N. 89, pp. 25-47.

\section{Planteo de la cuestión que nos ocupará ${ }^{2}$}

Dentro de las escuelas clásico-finalistas (vinculadas doctrinalmente con la tradición política tomista), que en principio aceptan al bien común

2 Es la intención científica del autor poner a consideración este estudio crítico en la revista académica de mayor alcance en Argentina dentro del ámbito de los cultores del pensamiento clásico y tomista dedicados a los saberes jurídico-políticos. 
político como causa final del orden político y a la politicidad natural como una propiedad de la esencia humana, no hay acuerdo -en especial, hoy-respecto de la naturaleza y de la función de aquel fin común.

Como veremos en estas líneas, la afirmación de que el bien común consiste en un conjunto de condiciones para la perfección de las personas (y otras formulaciones reconducibles a la misma idea) entra en conflicto con 1) la tesis axial tomista de la politicidad natural; 2) la afirmación de que la sociedad (política) tiene, en tanto tal, existencia real; 3) el conocimiento moral del hombre que obra con rectitud. Es decir: la tesis es inconciliable con la tradición dentro de la que se pretende engastarla; y es inviable como posición sobre la realidad objetiva, "en las cosas mismas" -a las que insta a ir Husserl. Analicemos y mostremos en lo que sigue cada uno de tales problemas.

\section{Conjunto de condiciones y politicidad natural}

\section{Una problemática inteligencia-y formulación-del concepto de bien común}

Tómense algunos casos significativos: a) un relevante filósofo del Derecho iusnaturalista como John Finnis. El catedrático de Oxford y de Notre Dame determina, sí, que el elemento constitutivo de un grupo como familia, equipo, Estado, etc., consiste en compartir un objetivo, al cual se le llama "bien común (common good)". Mas este fin constitutivo (causa final) viene definido como conjunto de condiciones ("set of conditions") que capacita a los miembros de un comunidad para alcanzar por sí mismos los valores que buscaban al nuclear$\mathrm{se}^{3}$; b) un influyente filósofo social e internacionalista del pasado siglo, como J. T. Delos. En su clásica obra, La société internationale et les principes du droit public, define a la causa final del Estado -el bien común- como el conjunto completo de las condiciones ("l'ensemble complet des conditions") materiales y morales para la vida y el desarrollo de los hombres ${ }^{4}$. Tal había sido, asimismo, su concepción del bien común en la muy influyente traducción comentada de la Suma Teológica del Aquinate; c) un moralista como Victor Cathrein. Este autor, en las innumerables ediciones de su conocido manual -que comienzan en 1895-, ha afirmado que la causa final de la sociedad política debe definirse como el conjunto de las condiciones requeridas ("complexus condicionum requisitarum") para la felicidad de los miembros de la sociedad 5 .

3 Finnis, J. (1993). Natural Law and Natural Rights. Oxford, O. U. P., 152-155.

4 Delos, J. T. (1950). La société internationale et les principes du droit public. París. Pédone, 136.

5 Cathrein, V. (1932). Philosophia moralis. Friburgo de Brisgovia. Herder, 411. 
Tal concepción acerca de la causa final del grupo (en particular, en lo referente al Estado -entendido aquí como comunidad política-) aparece habitualmente recogida por la filosofía política y jurídica hispanoamericana. Así, podemos citar el ejemplo que ofrecen dos ilustres académicos y hombres públicos, como el filósofo y presidente de la Corte Suprema de Justicia de la República Argentina, Tomás Casares ${ }^{6}$, y el catedrático y padre de la constitución chilena, Jaime Guzmán Errázuriz ${ }^{7}$. Y nos eximimos explícitamente de citar a otros connotados y calificados autores, que no trepidan en seguir la que veremos constituye una insostenible formulación.

Digamos desde ya que semejante caracterización de la naturaleza y de la función del fin común - a pesar de su relativa vigencia doctrinal-resulta problemática. En efecto, como se mostrará brevemente infra, en esta concepción el fin común como causa final de la sociedad aparece incluso comprometido en su especificidad de causa $y$ de fin.

Así pues, entre quienes sostienen la causalidad social del fin aparece una cuestión a dirimir, toda vez que dentro de esas corrientes finalistas no hay verdadera coincidencia in re (real, no meramente nominal) sobre cuál sea la causa final de la sociedad. Corresponde entonces, ineludiblemente, sopesar si acaso el bien común consiste en la protección de bienes y derechos particulares; y si acaso amerita ser acríticamente aceptada en sede científica la formulación del bien común como conjunto de condiciones para la perfección de las personas.

\section{Sobre la tesis (madre) de la promoción y protección de los bienes particulares como fin de la comunidad política}

\section{a) Las aporías a que conduce}

A partir de las posiciones últimamente presentadas cabe considerar la posibilidad de que el primer principio del todo político pueda ser reducido a una pluralidad de fines, o al conjunto de los fines de las partes -sean o no interdependientes. Ése sería el caso si la causa final del Estado se redujese a los derechos y bienes individuales y grupales, tal como a veces se propone.

6 Casares, T. (1973). La justicia y el derecho. Buenos Aires. Abeledo-Perrot, 35.

7 Guzmán, J. (1996). Derecho Político. Santiago de Chile. Ed. U. C. de Chile, 30 y 31. 
Ante esta posibilidad, resulta razonable poner de manifiesto algunos de sus presupuestos y consecuencias. Cada uno de los bienes comunes correspondientes a las sociedades infrapolíticas es específicamente inferior al bien común político. Y su reunión total no alteraría cualitativamente su carácter infrapolítico. Además, si el fin común político consistiese en el reaseguro de los fines infrapolíticos, entonces ya no se trataría de un fin en el que se estructura un orden de perfecciones participables, sino de tantos fines cuantas partes haya. Con lo cual se plantean ciertas dificultades. Por un lado, el fin que aúna y unifica no es uno ni unificante, porque no es causalmente común y aparece como formalmente múltiple. Por otro, no existe un fin distintivamente político, superior al reaseguro de los bienes grupales e individuales de las partes. Ambas dificultades comprometen la especificidad y la naturaleza de la realidad política, y son solidarias. La primera pone en tela de juicio la causación y la supraordenación de su fin propio; la segunda oscurece la necesidad de la vida política como promotora de un bien comprehensivo aunque cualitativamente superior al de los grupos y los individuos. Porque conviene advertir el status axiológico que investiría a este "bien común político": sería un bien instrumental al servicio de los bienes particulares: es decir, su rango sería inclusive menor al de éstos últimos.

Es necesario recordar que la nota de común que se atribuye al fin de la sociedad política consiste en ser común por la causación. Se trata, concretamente, de una causa que atrae por modo de fin y que produce efectos en todo miembro de la comunidad de la que es causa. El bien natural perfecto (político) convoca y perfecciona como un fin que no por común deviene ajeno. No es un universal lógico sino, precisamente, aquello que extiende su causalidad más allá de un solo individuo gracias a su valiosidad intrínseca y a su riqueza perfectiva. En efecto, hay comunidad de causación si lo común es más perfecto que lo particular; en el plano de la causalidad final esto equivale a mayor plenitud de bien. Luego, si el fin político no es más perfecto que los fines infrapolíticos, no hay causa final para la sociedad política $^{8}$. Ante lo cual se plantean nuevamente dos alternativas: o negar

8 Sobre este tema en el Aquinate cfr., entre muchos otros pasos, S. Th., I-IIae., 90, 2 c.: "[...] porque toda parte se ordena al todo como lo imperfecto a lo perfecto, el individuo es parte de la comunidad perfecta [...] la comunidad perfecta es la ciudad, como dice el Filósofo en el libro I de la Política"; ibíd., I-IIae., 90, 3 ad 3: "[...] como el bien de un hombre no es el último fin, sino que se ordena al bien común, así también el bien de una familia se ordena al bien de una ciudad, que es la comunidad perfecta"; ibíd., II-IIae., 58, 9 ad 3um: "[...] el bien común es el fin de las personas singulares existentes en la comunidad" (se utiliza la editio altera romana, Roma, 1894). Ésta y otras cuestiones conexas son tratadas en Castaño, S. R. (2011). Los principios políticos de Sto. Tomás en entredicho. Una confrontación con Aquinas, de John Finnis. Estudio Preliminar de Camilo Tale. $2^{\text {a }}$ edición. La Plata. UCALP. 
la existencia del todo de orden político (o sea, de la comunidad política o Estado) debido a la carencia de un fin real y propio que lo origine -sobre este tema volveremos en el parágrafo III, sobre "Conjunto de condiciones y realidad de la sociedad política". O cuestionar el carácter natural de la sociedad política, tal como la tradición clásica y cristiana (en particular: tomista) lo ha entendido. Porque para esa tradición la nota de natural referida a la vida política implica el hallarse primariamente abocada a la consecución de un orden específico de bienes exigidos por la naturaleza humana, y no a la evitación de daños o al subsanamiento de defectos. Es decir, la aceptación de la natural politicidad implica la aceptación de que la vida política es un bonum honestum, un bien simpliciter y no un remedio de males, a la manera en que paradigmáticamente lo planteó Rousseau: se sufre la vida política como quien sufre se le ampute un brazo para no morir de gangrena ${ }^{9}$. Esto equivale, por un lado, a la imposibilidad de resolver el fin político en el socorro circunstancial a otros grupos (de allí que el principio de subsidiariedad mismo se desvirtúe si se lo divorcia del de la primacía del bien común, llamado también "principio de totalidad"). Así como también, por otro lado, la afirmación de la natural politicidad impide explicar la presencia de lo político a partir de insuficiencias humanas contingentes -0 de un avatar histórico ${ }^{10}$.

\section{b) Su filiación doctrinal}

El principio de la politicidad natural del hombre conlleva necesariamente -lo reiteramos- la afirmación de que el fin de la sociedad política es un bien común propio y específico, irreductible y supraordenado respecto de todos los otros fines naturales de sus miembros ${ }^{11}$. Ahora bien, si la función del orden político se reduce a proporcionar ayuda para que los grupos meno-

9 Rousseau, J. J. (1964). "Discours sur l'origine et les fondements de l'inégalité parmi les hommes”. En Oeuvres Complètes. T. III (Écrits politiques), París. Ed. de la Pléiade, 178.

10 Para el teólogo Santo Tomás, en efecto, en estado de naturaleza íntegra la politicidad natural seguiría plenamente vigente, y por esa razón también habría mando y obediencia (cfr. S. Th., Ia., 96, 4). La del Aquinate a este problema es la respuesta de un aristotélico cabal. Sobre el concepto aristotélico de politicidad natural, cfr. Castaño, S. R. (2005). "La politicidad natural como clave de interpretación de la historia de la filosofía política". En Sergio R. Castaño - Eduardo Soto Kloss (editores). El derecho natural en la realidad social y jurídica. Santiago de Chile. Academia de Derecho UST, 277-307.

11 Para el sentido de "naturale" en su aplicación a la vida social y política en Santo Tomás vide el repertorio de textos que trae Utz, A. F. (1960). Éthique sociale. Trad. fr. Étienne Dousse. T. I. Friburgo. Éd. Universitaires de Fribourg, 231-237. 
res alcancen sus objetivos, luego el fin mundanal de los hombres resulta ser extra- (o pre-) político. Lo político fungiría como allanador de obstáculos, o removedor de impedimentos circunstancialmente atravesados en el camino de los grupos infrapolíticos. Éstos parecerían ser, de suyo, autosuficientes. Pero se encontrarían necesitados de ayuda y, sobre todo, de protección. Se plantea, aquí, una situación compleja: sociedades autosuficientes requerirían la presencia de otra que, sin un fin específico, les creara condiciones favorables y las protegiera. La causa de la vida política se identificaría, entonces, con la causa de que aquellas sociedades reclamen apoyo en sus desfallecimientos y protección ante peligros. Tal causa no sería, principalmente, sino la debilidad y maldad humanas.

Ésta es, precisamente, la doctrina del fundador del liberalismo político, John Locke. En efecto, toda su caracterización del estado de naturaleza en sentido estricto es el más decisivo argumento lockeano a favor de la suficiencia de la vida prepolítica. La aparición de lo político supone un estadio lógicamente ulterior, representado por la aparición de la maldad humana y la consiguiente caída en estado de guerra (en el que se echa de ver la versión secularizada del dogma del pecado original). El Estado adviene y es exigido a partir de la necesidad de evitar las injurias mutuas y de proveer seguridad a los bienes asequibles por los individuos y los grupos fuera de la órbita política. Es un reaseguro histórico de la libertad primitiva y de sus fines particulares. Lo político aparece, así, como un remedio, en la medida en que sirve para paliar los defectos del estado de guerra -y no para promover una órbita de perfecciones humanas superior a las perseguidas por los grupos domésticos o económicos.

Es manifiesto el alcance de la hipótesis de tal estado de naturaleza respecto de la valoración del orden político. Ahora bien, Locke, además, confirma de manera expresa esa concepción del Estado en el parág. 128 del Second Treatise on Government ${ }^{12}$, al relacionar causalmente su existencia con la maldad moral. En efecto, dice allí, todos los hombres forman una comunidad; y si no fuera por la corrupción y el vicio de individuos degenerados, no sería necesario agruparse pacticiamente en sociedades menores (políticas); bastaría con la gran comunidad humana. Posiciones como la de Leo Strauss, que acercan el núcleo del pensamiento político de Locke al de Hobbes, encuentran ratificación explícita en ese pasaje ${ }^{13}$.

12 Se utiliza la edición de C. B. Macpherson (1980). Indianapolis. Hackett.

13 Strauss, L. (1970). Natural Right and History. Chicago. Chicago U. Press, 166. En Locke, J. (1952). A Letter concerning Toleration (ed. Sherman). Chicago. Great Books, T. 35, p. 16, col. 1, encontramos un pasaje paralelo. 
A tenor de lo dicho no resultaría impropio calificar como primariamente represivo el orden político. Este carácter policial del Estado aparece también explícitamente afirmado por Locke. Así, por ejemplo, en el parág. 88 , en tren de distinguir las notas específicas de la sociedad política, nuestro autor señala el papel punitivo como un eje de sus funciones y de su mismo ser ${ }^{14}$.

Si la actividad del Estado se limita, básicamente, a tratar de remediar los efectos de la maldad moral, es que los fines humanos son lógicamente previos e independientes respecto del orden político. Éste se justifica en la medida en que resguarde imparcial y eficazmente los bienes particulares y sus correspondientes derechos. En sentido estricto, ya no puede afirmarse el bien común como fin de la comunidad política; no habría, como se ha dicho, un orden de bienes superiores participables que originara la vida del todo político en tanto tal, es decir, fines que excedieran el ámbito de los individuos o los grupos infrapolíticos.

No otra cosa afirma el Treatise. Constituye un tópico de la obra el aserto de que la razón por la cual los hombres se integran y permanecen en sociedades políticas es la protección de su vida, libertad y propiedad; si bien Locke prefiere hablar, concisa y significativamente, de la protección de su propiedad privada ${ }^{15}$. Locke, con todo, se refiere en un escueto pasaje al beneficio que la asistencia mutua provee a los individuos integrados en sociedad política. Sin embargo, la necesidad que esto conlleva es la de deponer la libertad natural y el poder de ejecutar propios del estado de naturaleza, para sostener el poder de la comunidad. Y, además, el fundamento de la obligación que genera consiste en la reciprocidad con que los demás observan igual conducta; es decir, la justicia de resignar el poder natural reside en la

14 "And thus the common-wealth comes by a power to set down what punishment shall belong to the several transgressions which they think worthy of it, committed amongst the members of that society (which is the power of making laws) as well as it has the power to punish any injury done unto any of its members, by any one that is not of it (which is the power of war and peace); and all this for the preservation of the property of all the members of that society, as far as is possible" (destacado original).

15 Cfr. parágs. 85, 94, 120, 124, 127. El tema de la propiedad privada ocupa un lugar central en la filosofía política de Locke; un largo capítulo del Treatise le está dedicado. Es pertinente remarcar que la vida económica se desenvuelve ya dentro del estado de naturaleza; además, Locke da por legítima la acumulación de propiedad más allá de las necesidades, y la desigualdad social que esto provoca. Lo político aparecerá como consecuencia del desarrollo de las relaciones económicas y, puede decirse, a ellas subordinado. Respecto de este tema, cfr. Strauss, L. (1970). Ob. cit., 234 y ss.; Bobbio, N. (1963). Locke e il diritto natural. Turín. Giappichelli, p. III, esp. 216 y ss.; Macpherson, C. B. (1989). The Political Theory of Possessive Individualism. Oxford. O.U.P., 197-221; Ricci Garotti, L. (1961). Locke e i suoi problemi. Urbino. U. de Urbino, 69 y ss.; Pezoa, A. (1997). Política y economía en el pensamiento de John Locke. Pamplona. EUNSA, esp. 115 y ss. (sobre el fin político). 
situación contractual de las partes. Se trata, pues, de una alusión aislada a la colaboración social (aunque no parece señalarse como actor a la sociedad política, sino a los grupos e individuos que la integran); alusión diluida en la temática recurrente de la necesidad de un poder común protector de la propiedad, fruto de un acuerdo subjetivo. Por todo ello resulta coherente que el término -raro en Locke- de "common good", estampado enseguida, sea reducido nocionalmente a la protección de la propiedad ${ }^{16}$, i. e., al conjunto de los intereses individuales ${ }^{17}$.

\section{c) Algunos corolarios}

Proponer la promoción de bienes infrapolíticos como fin del cuerpo político suscita ciertas aporías, cuya solución coherente demanda, sin lugar a dudas, una opción radical. La conjunción de autosuficiencia (natural) prepolítica con debilidad (¿caída?) histórica -que de alguna manera se sigue a partir de la reducción del fin político a la protección de fines particulares- es compatible con los principios contractualistas sobre el origen y la naturaleza del Estado, pero no con el de la politicidad natural. En otros términos, resulta legítimo concluir que no hay conciliación coherente entre este último principio y la tesis que se viene cuestionando. Pues tal conciliación supone aceptar posiciones contractualistas e individualistas (en sentido filosófico-social), cuyos presupuestos se hallan en franca contradicción con los del realismo clásico y tomista. Por todo ello no resulta aventurado plantear radicalmente la siguiente opción: o se sostiene la politicidad natural, o se sostiene la promoción y protección de los bienes y derechos particulares como fin de una sociedad política que ya no tendrá carácter natural. Para el filósofo del Derecho y del Estado, la aceptación de una tesis implica el rechazo de la otra.

16 Cfr. pgf. 130 y 131; ver, asimismo, A Letter concerning..., p. 3 col. 1 y p. 16 col. 2 de la ed. cit.

17 Cualquier matiz que introduzcan investigaciones exegéticas recientes en algunas obras de Locke de prácticamente nula trascendencia no empece la significación de esta obra canónica respecto del origen, sentido y valor del orden político según el autor. Así, por ejemplo, la preservación de la supervivencia de los pobres -y ello además por motivaciones de índole confesional-ni resulta contradictoria con la tesis de la acumulación de propiedad más allá de las necesidades, ni menos introduce una alteración en los ya expuestos fundamentos de la vida política en Locke. Dado el específico tema del presente artículo no podemos extendernos en esta cuestión exegética. 


\section{La identificación del bien común con el "conjunto de condiciones para la perfección de las personas" como una variante de la misma tesis}

Los presupuestos de la formulación que identifica al bien común con el "conjunto de condiciones para la perfección de las personas" la reconducen, de hecho, a la posición que se viene criticando.

En primer lugar, si se acepta que el bien común político es la causa final de la comunidad política, luego no se puede afirmar que la causa es condición, pues, como leemos hasta en los manuales mismos, "la condición es el requisito o la disposición necesaria para el ejercicio de la causalidad: algo meramente auxiliar, que hace posible o impide la acción de una causa; la condición en cuanto tal no posee causalidad. La existencia de adecuadas condiciones climáticas, por ejemplo, es condición para que se desarrolle una prueba deportiva, pero no es su causa"18. Por otra parte, la concepción del bien común como condición implicaría la afirmación de los bienes particulares como causas. Respecto de éstos el bien común representaría una suerte de medio, mas nunca de fin.

En función de lo expresado, puede afirmarse, en síntesis: si el bien común es condición para la consecución del bien particular, entonces, el bien común ni es causa (pues es condición) ni es final (porque tiene razón de medio). Y la causa final se identificaría, también aquí, con el conjunto de los fines particulares.

Una vez más corresponde plantear una opción como la de marras. $O$ se sostiene que el bien común es causa final de la sociedad o se identifica el bien común con un conjunto de condiciones. Para el filósofo del Derecho y del Estado, la aceptación de una tesis implica el rechazo de la otra.

\section{Conjunto de condiciones y realidad de la sociedad política}

\section{Recapitulación}

En el anterior parágrafo hemos analizado las opciones doctrinales que se imponían a partir de la asunción de ciertas tesis -que se reconducen todas a una matriz principial común. Esas tesis son, por ejemplo, que "el fin de la comunidad política es la protección de los bienes y derechos del indivi-

18 Alvira, T.; Clavell, Ll.; Melendo, T. (1982). Metafísica. Pamplona. EUNSA, 187 (destacado original). 
duo"; o que "el fin de la comunidad política es la persona humana"; o que "el bien común es el conjunto de condiciones para la perfección de la persona". Hemos dicho que la aceptación de tales tesis (asumidas sensu stricto) exige renunciar al principio de politicidad natural. Ahora bien, juzgamos que las consecuencias que se siguen de la asunción de esas tesis son más radicales incluso que la necesidad de renunciar al principio aristotélico y tomista de justificación de la vida política.

Como corolario del anterior parágrafo II, esbozaremos en éste un planteo de dichas consecuencias, en el plano sistemático (es decir, con la intención de llegar "a las cosas mismas"). Se tratará de un breve intento de dilucidación de algunas consecuencias de asumir formulaciones impropias, en sede filosófica (científica), a la hora de determinar la causa fundamental de la sociedad política en particular -y de toda sociedad en general.

\section{Negación de las causas y negación del estatuto ontológico de la sociedad}

Si la comunidad política, en sentido estricto, se halla no ordenada al bien común sino al servicio del bien del individuo, luego la comunidad política es instrumento del individuo. Ahora bien, la causa eficiente instrumental, en tanto instrumental, no ejerce causación por su propia virtud, sino que sólo actúa movida y utilizada por la causa principal ${ }^{19}$. En la causalidad instrumental se produce una sola acción, efectuada por la causa principal a través del instrumento ${ }^{20}$. Así, a partir de semejante presupuesto, la causación eficiente de la comunidad política se vería falseada.

Por su parte, el fin de la operación de la comunidad política se reduciría a un bien "común" que en realidad ya no sería propiamente tal (común y supraordenado), sino un repositorio de bienes con razón de útiles, es decir, de medios, necesarios para el cumplimiento del fin del individuo (de cada individuo). Por ello, la causa final resultante de tal entidad colectiva no sería una causa final que aunase y fundase una sociedad autárquica-porque habría tantas causas finales cuantos individuos-; $y$ todos los bienes de las sociedades en las que el hombre se integra (desde el bien político hasta el familiar) serían medios útiles insertos en el despliegue operativo de cada individuo persiguiendo su finalidad individual. Y, nuevamente, nótese: el bien común político tendría inferior rango axiológico al bien particular, por cuanto no sería sino su instrumento (como bien útil).

19 Cfr. Tomás de Aquino. S. Th., III ${ }^{\mathrm{a}}, 64,5$ c.

20 Ibíd., III ${ }^{\mathrm{a}}, 19,1$ ad 2 um. 
Este planteo corresponde, precisamente, a la ontología social fundamental del individualismo. En efecto, las concepciones metafísicas que se hallan a la base del individualismo tienden a confundir la naturaleza de todo bien común con la de un medio de los fines del individuo, el cual incluso a veces aparece como único y auténtico fin de la praxis. Ejemplo canoro de lo cual nos lo ofrece La personne et le bien commun, de Jacques Maritain, especialmente en su parte IV, referida a las relaciones entre persona y sociedad $^{21}$.

Dado que la causa final es la ratio causalitatis de la causa eficiente, una vez negada la causación propia del bien común como causa final del orden social en tanto social, queda por necesidad tergiversada la correspondiente causación eficiente de la sociedad persiguiendo su fin. Y como consecuencia de todo ello se ve comprometida, como demostraremos enseguida, $l a$ realidad misma de la sociedad.

En efecto, si se acepta racionalmente que el nombre de "sociedad" significa un ente real (accidental, de la categoría de relación) consistente en la "unión de hombres para obrar mancomunadamente algo en común" 22 -y no una agencia instrumental que provee los bienes útiles para los individuos-; debería entonces decirse que la sociedad política no sólo no es natural (como concluíamos en el anterior parágrafo), sino que no existe en tanto tal. Pues ella, de hecho, se reduciría a la mera realidad de los individuos actuantes en pos de sus fines individuales -y esta conclusión, necesariamente, le cabría a toda especie de sociedad. Podríamos resumir nuestra tesis como sigue. Según el planteo que en el plano filosófico-social puede denominarse "individualista", la sociedad consiste en una suma de individuos (vinculados por relaciones de coordinación); y el fin común no es tal, sino una yuxtaposición de fines particulares. En este planteo individualista, "sociedad" es un nombre cuyo referente real no tiene existencia: "sociedad" significa un ente de razón (sin fundamento in re) que, a su vez, se corresponde (en la realidad extramental) con un mero agregado de individuos contiguos en el espacio y simultáneos en el tiempo, entablando eventuales relaciones de coordinación -interdependientes, pero no integrados en un todo de orden-, con sus respectivos intereses yuxtapuestos. En esta posición, coherentemente asumida, la sociedad, como ente real distinto de la sumatoria de sus partes (i. e., como un todo práctico-finalista), en sentido estricto, no existiría.

Las consecuencias de tales ideas en el plano axiológico son evidentes. Como ya hemos mostrado en el parágrafo II, si tal fuera el estatuto ontológi-

21 Edición francesa de Desclée, 1946; hay trad. cast. de L. de Sesma. Buenos Aires. Club de Lectores, 1968 y 1981.

22 Tomás de Aquino. Contra impugnantes Dei cultum et religionem, 2, 2. 
co de la comunidad política, la vida política no resolvería su sentido y su valiosidad en un fin peraltado (un bonum honestum et principalissimum) que no está al alcance de los grupos infrapolíticos y de los individuos obrando aisladamente -fin común coronado por el cultivo del saber, la transmisión de un talante comunitario histórico, la vida amical y virtuosa-; sino que la vida política fundaría su justificación en la necesidad de la acción de un poder que socorriera a esos individuos en sus desfallecimientos y que les impidiera colisionar y hacerse daño entre sí.

\section{El bien común y la perfección de la persona: la solución tomista}

Pero se preguntará: ¿y la dignidad de la persona? ¿Y el valor del hombre en su racionalidad, creaturidad, irrepetibilidad, indisponibilidad? ¿Acaso el verdadero bien de cada individuo no constituye un fin que, sobre todo hoy, no se debe negociar? Entonces, el bien común político, ¿es un fin ajeno al bien de cada persona? La formulación del bien común como "el conjunto de condiciones para la perfección de la persona", ¿no representa acaso el modo de atender a estas exigencias, aunque sea con una semántica errónea?

La respuesta racional a estas cuestiones que apelan a nuestra conciencia la ofrece la distinción metafísica clave entre fin qui, quo y cui, en su aplicación al bien común. Ella fue utilizada por primera vez en la época contemporánea por Pierre Philippe ${ }^{23}$; y, sobre todo, desarrollada por Louis Lachance ${ }^{24}$. En su estela también hicieron suya esta distinción varios representantes de la escuela argentina del Derecho Natural, entre otros, Guido Soaje Ramos ${ }^{25}$, Avelino M. Quintas ${ }^{26}$ y Héctor H. Hernández ${ }^{27}$-y, gracias a todos ellos, quien esto escribe. La no ajenidad del bien común respecto de la persona se explica a partir del carácter de ésta como fin cui, sin necesidad de hacer de la persona humana el fin de la sociedad. Sobre el fin cui dice Lachance, avalado por la autoridad de Tomás de Aquino: "[...] designa el

23 Cfr. Philippe, P. (1938). Le rôle de l'amitié dans la vie chrétienne selon S. Thomas d'Aquin. Roma. Angelicum, 40-42.

24 Cfr. Lachance, L. (1965). L'humanisme politique de S. Thomas d'Aquin. París-Ottawa. Éd. Du Lévrier (edición original de 1939), 321 y ss.

25 Cfr. Soaje Ramos, G. (2005). "Sobre la politicidad del derecho". $1^{a}$ ed. 1958; reeditado en Castaño, S. - Soto Kloss, E. (2005). El derecho natural en la realidad social y jurídica, citado supra, $42-44$.

26 Cfr. Quintas, A. M. (1988). Analisi del bene comune. Roma. Bulzoni (1a . ed. 1979), 174 y ss.

27 Cfr. Hernández, H. H. (2000). Valor y Derecho. Buenos Aires. Abeledo-Perrot, 101 y 102 . 
sujeto privado de la bondad del fin y que, cuando lo alcanza, se convierte en beneficiario de sus enriquecimientos. Va de suyo que no puede haber finalidad sin que haya un sujeto al que conviene un bien cualquiera. El bien es fin y el sujeto que sufre su atracción se ordena a él. De modo que no es él quien es el fin, sino el objeto que lo atrae. Él quiere para sí el objeto que le conviene, pero la causa, el motivo por el cual lo quiere para sí reside en la bondad encarnada en el objeto" (destacado original). Lachance ejemplifica este principio con la relación entre Dios y las criaturas; éstas, en efecto, se perfeccionan alcanzando a Dios, pero Dios no es el medio para los fines de las criaturas. La inadvertencia de estos distingos podría llevar, por ejemplo, a postular a Dios como un medio o instrumento en el camino del hombre hacia su perfección individual sobrenatural.

De entre tantas conclusiones posibles de este punto 3, sólo se nos ocurre insistir en que el objeto de la filosofía social y política es asequible a la razón natural; y que, por lo tanto, los filósofos de la Sociedad, la Economía, el Derecho y la Política, cuando hablan como tales están obligados a contribuir a la verdad atendiendo a las exigencias racionales de su objeto.

\section{Sentido en el que puede ser licito mencionar un "conjunto de condiciones" al referirse al bien común}

En Lecciones de Filosofía del Derecho ${ }^{28}$ Camilo Tale propone utilizar la doctrina de la analogía (de atribución) para dar lugar y justificar la inclusión del conjunto de condiciones en la noción de bien común. Tale distingue entre fin y conjunto de condiciones y afirma taxativamente que el bien común social y político tiene razón de fin; y que, por lo tanto, consiste en la perfección misma que plenifica al grupo. Se trata, además, de la causa que convoca a éste y que lo constituye en su realidad de tal. Así pues, el bien común social no es -en sentido propio- un medio. Luego, al ser fin y causa final, no puede ser definido por las condiciones. No obstante, es verdad que el fin se realiza a través de ciertos medios; y si a esos medios o vías -institucionales, ante todo- se acepta denominarlos "condiciones" (en la medida en que favorecen o allanan la acción causal), entonces cabría incluir -aunque siempre en sentido derivado y secundario- las condiciones como una parte del bien común. Ahora bien, en tanto "bien común" se dice de tales condiciones de modo secundario y derivado, no cabría significar la naturaleza del bien común por medio de la locución "conjunto de condiciones", concluye

28 Tale, C. (1995). Lecciones de Filosofía del Derecho. Córdoba. Alveroni, 254-256. 
Tale. Nótese que allí sólo se está identificando los auténticos medios institucionales para el cumplimiento del fin participable, e incluyéndolos (como partes subordinadas) dentro de la órbita del bien común ${ }^{29}$. Pero no se está subordinando el bien común al bien particular, ni haciendo de la comunidad política y de su fin un instrumento del individuo, como necesariamente lo implica la definición del bien común como el conjunto de las condiciones para la perfección de la persona. Pues en este caso se trata de otra significación de "condiciones".

Por lo demás, repárese asimismo en que los agentes comunitarios (individuos, familias, cuerpos intermedios y el Estado mismo a través de las "instituciones personas" y las "instituciones cosas") cuando actúan persiguiendo el bien común político lo hacen operando sobre las "condiciones", así entendidas: a través de la ley la potestad pública atiende al imperio de la justicia; a través de la subvención de los organismos científicos esa misma potestad atiende a la consecución de bienes sapienciales; a través de la fundación de una biblioteca agentes privados atienden a la promoción de la educación; etc. Es decir que el objeto inmediato de la acción de los agentes sociales, tanto políticos (los poderes del Estado) como infrapolíticos (asociaciones civiles, fundaciones, y los demás grupos como la familia, en tanto ordenen algunas de sus acciones directamente al bien común), suele recaer sobre realidades de naturaleza institucional, por medio de las cuales se promoverá el bien común. Luego, debe reconocerse que la acción de los agentes sociales y políticos recae en general sobre objetos que tienen razón de medio, instrumento o condición allanante respecto del fin. Pero ni la ley, ni el organismo científico, ni la biblioteca ut sic son el fin al que se ordena la acción de esos agentes, ya que ese fin (no sólo como finis operis sino incluso como finis operantis) radica en una dimensión del bien común político.

En conclusión, cualquier rescate del "conjunto de condiciones" -rescate circunscripto, reitérese, a su categorización como mero analogado secundario, por el cual nunca cabría tampoco lícitamente definir al bien común- no alcanza a la formulación de "conjunto de consideraciones para la perfección de la persona". Pues ésta resulta insalvable como definición o caracterización del bien común.

29 En la línea en que Arthur-Fridolin Utz se había referido a las condiciones institucionales y económicas como "hecho común exterior", subordinado al cumplimiento del "bien común inmanente", auténtico y propio bien común de la sociedad. Cfr. Utz, A. F. (1960). Éthique Sociale. T. I, 95 y ss. 


\section{Equívocos a despejar}

El bien común (político) es el fin de la comunidad política; y ésta obra, en tanto tal, bajo la conducción de sus potestades supremas. Luego, el fin específico de los poderes públicos es el bien común político. Con todo, repárese en que el bien común también es fin para los cuerpos intermedios y las familias; los cuales -sin desconocer el fin común propio que los constituye como cuerpos intermedios y como familias- se hallan obligados a finalizar sus respectivas conductas consociadas como debe hacerlo toda parte de la comunidad, i. e., armonizando y subordinando sus bienes comunes específicos (particulares) al bien de la comunidad autárquica ${ }^{30}$. Asimismo, como hemos visto en Tomás de Aquino, el bien común político "es fin de las personas individuales que viven en la comunidad". Así pues, el bien común político es perseguido indirecta, $\mathrm{y}$, a veces, directamente, por los individuos y los grupos infrapolíticos -en tanto partes de la comunidad política-, y no sólo por el poder del Estado, cual si se tratase de un agente aislado y divorciado del todo de orden comunitario. Es el conjunto de la comunidad política-sociedad de sociedades_ ${ }^{31}$, bajo el imperio rector del poder del Estado, el que tiene como fin propio, directo (inmediato) y específico, al bien común político.

Como síntesis de estos puntos 4 y 5: no debe reducirse el bien común a la categoría de un objetivo perseguido meramente por los titulares del poder del Estado; así como tampoco debe confundirse el bien común -como fincon los medios (en sentido lato, que abarcan hasta los fines $q u o^{32}$ ) a través de los cuales se lo promueve.

30 El concepto de autarquía (política) es central para la comprensión de la naturaleza y sentido de la comunidad política. Para ese concepto en la ética, la Economía, el Derecho y la Política, vide Castaño, S. R. (2000). Orden político y globalización. El Estado en la contingencia actual. Buenos Aires. Ábaco de Rodolfo Depalma, especialmente capítulos III y VI; y para su validez sistemática como clave del orden político, vide del mismo (2005). El Estado como realidad permanente. Buenos Aires. La Ley (1 $1^{\mathrm{a}}$. edición 2003), especialmente caps. VI, VII y VIII.

31 En esta nota de la comunidad política, la de constituir una "sociedad de sociedades" -como la denomina Juan A. Widow: vide Widow, J. A. (1988). El hombre, animal politico. Santiago de Chile. Academia de Educación, 75-76-, se asienta el principio de subsidiariedad, de valor axial para el recto desenvolvimiento de la vida estatal en tanto vida humana. Sobre la concreción de ese principio en el orden jurídico-político, cfr. Soto Kloss, E. (2009). Derecho administrativo. Temas fundamentales. Santiago de Chile. Lexis-Nexis, 67 y ss. Aprovechamos para decir aquí que respecto de varias de las cuestiones discutidas en las páginas de este artículo mucho debemos al diálogo que hemos mantenido con este ilustre amigo a lo largo de años.

32 Como fin quo designa Guido Soaje Ramos el plano institucional, en sentido lato, al que nos hemos referido supra -cfr. Soaje Ramos, G. (1985). "El bien común político en el Aquinate: ocho tesis", ponencia a la Semana Tomista de 1985-. 
Por último, y en general, no debe identificarse primacía y supraordenación del bien común político con 1) licuación de todas las órbitas sociales en el Estado (comunidad); ni, a fortiori, 2) asunción por el Estado (gobierno / administración) de todas las actividades y operaciones propias de los diversos órdenes sociales. No es ocioso reiterar una vez más la verdad palmaria de que la primacía del bien común no implica totalitarismo ni estatismo. Es que la naturaleza y las propiedades del bien común político no pueden predicarse idénticamente del Estado (gobierno/administración), ni tan siquiera del Estado (comunidad) en sí mismo considerado.

En este lugar resulta pertinente (pensando también en quienes han echado de menos una) citar la respectiva definición de José María Medrano: "[...] bien común político es el bien humano social proporcionalmente participable que el Estado, como sociedad autárquica y unidad de orden, puede proponerse, puede construir y puede alcanzar mediante sus acciones y operaciones propias, en las cuales cada miembro desempeña una función parcial"33.

\section{Conjunto de condiciones y experiencia virtuosa}

\section{El posible conflicto entre las obligaciones para con Dios y las imposiciones del régimen político vigente}

Se halla pues al alcance del conocimiento humano natural la impugnación de la idea de que la comunidad política y su bien común serían instrumento y medio de la sumatoria de los individuos y de sus bienes. Y esas verdades -tal vez con mayor patencia aun-se le manifiestan al hombre que quiere ya no especular sobre el bien humano sino concretarlo en su vida personal, a partir del conocimiento de los principios de la ley natural (los cuales, en el caso de los principios primarios, son de aprehensión inmediata y asequibles a todo individuo adulto y sano). Por ello, para el apetito rectificado por los principios de la ley natural la patria no es un instrumento, ni un medio. En efecto, el bien de la patria, como ha dicho el Aquinate erguido sobre la tradición griega y romana, es el bien común político bajo la formalidad de principio de nuestro ser $^{34}$. Así como tampoco deviene instrumento o medio en perspectiva religiosa: lo que un creyente podría lícitamente sostener, sí, es que ella debe ser un camino hacia Dios para todos sus miembros

33 Medrano, J. Ma. (2005). "Tomar en serio el bien común”. En Castaño - Soto Kloss. El derecho natural en la realidad social y jurídica, citado supra, 64.

34 Tomás de Aquino. S. Th., II-IIae., 101, 3 ad 3um. 
y habitantes, mas no que la patria está a su servicio y al del resto de los individuos.

Detengámonos un momento en lo últimamente dicho, para discutirlo a partir de un caso concreto, manifestativo de una posición hoy muy extendida. Autores connotados, a la hora de establecer la relación entre el bien común político y el bien de la persona individual, lamentablemente se hacen eco de la idea maritainiana de una distinción entre individuo y persona y, en línea con ella, proponen la siguiente graduación de bienes: "bien individual, bien común y bien personal”35. Luego, el bien común político se hallaría subordinado respecto del bien ultraterreno de la persona; rectius, el bien común sería un "instrumento" de ese bien personal. Tal vez aquí nos hallemos frente al eco de una tesis verdadera (i.e., la de la subordinación de la comunidad política a la ley de Dios); la cual, en categorías maritainianas, adquiere la formulación impropia, aunque hoy frecuente, que acabamos de leer. Sostenemos, por nuestra parte, que el principio de la subordinación del bien particular al bien común es inconmovible. Ahora bien, dada la unidad del hombre, ser llamado a la trascendencia, surge inevitablemente el problema del posible conflicto entre sus objetivas obligaciones para con Dios y sus obligaciones para con el régimen político vigente. Pero en realidad el problema teórico se resuelve, sin excepciones al principio de primacía del bien común, afirmando la subordinación -sin tensión ni conflicto objetivosdel bien individual al bien común en cada uno de los planos, natural y sobrenatural: del bien individual natural al bien común político (que no es lo mismo que "del individuo al Estado como organización de poder"); y del bien salvífico de la persona a su fuente, Dios. Pues -nótese- en este último plano el bien de la persona individual (gloria formal) también es cualitativamente menos rico que la Bondad divina misma. Ahora bien, existe, asimismo, una subordinación entre ambos planos (político y trascendente); no obstante, tal subordinación se da entre los bienes comunes mismos, es decir, que el bien común político debe subordinarse al bien sobrenatural, a la Verdad y al Bien trascendentes (y se le subordina necesariamente - desde un punto de vista deóntico-, si quiere ser pleno bien humano). Por ello una pretensión de bien común político que colisione objetivamente con la verdad eterna y con la ley de Dios no será verdadero derecho de la comunidad ni promoverá un verdadero bien del hombre. Así como tampoco se promociona el bien común

35 Así se expresa, por ejemplo, Guido Gonella, destacado académico y político italiano, uno de los padres de la constitución de 1949 -cfr. Gonella, G. (1959). La nozione di bene comune. Milán. Giuffrê, 47-51-. Respecto de la distinción maritainiana y de esta cuestión en general, cfr. Meinvielle, J. (1994). Crítica de la concepción de Maritain sobre la persona humana. Buenos Aires. Nuestro Tiempo, $1^{a}$. ed. 1948; Widow, J. L. (2004). La naturaleza política de la moral. Santiago de Chile. RIL, 233-257. 
atentando contra los principios primarios de la ley natural: los lacedemonios alcanzaron altas cotas de grandeza humana amando a la patria y a la tradición, sirviendo las leyes y cumpliendo su deber hasta la muerte; mas no arrojando niños desde la cima del Taigeto (aunque supuestamente creyeran que así fortalecían a la polis).

Así pues, la órbita política -ante todo entre los pueblos cristianos-debe subordinarse a la Revelación, cuya depositaria en la tierra es la Iglesia, su tradición y su doctrina auténtica. Pero esa subordinación debida se opera entre las órbitas o planos (o mejor, resolutivamente, bienes) natural-político $y$ salvifico-trascendente; $y$, a fortiori, entre el ordenamiento jurídico-positivo y la ley del Evangelio ${ }^{36}$.

\section{El conocimiento práctico propio de quien obra con rectitud. Un ejemplo existencial en el que resplandece la verdad práctica de la primacía del bien común sobre el bien particular de la persona: testimonio de patriota alemán}

A manera de remate de todas estas precisiones y reflexiones, vaya entonces, justamente, un testimonio autorizado. Con una autoridad fundada en la virtud y en la verdad -existencialmente asumida.

"La bomba del asesinato del rey de Serbia estalló en medio de nuestra pacifica vida estudiantil. Aquel mes de julio estuvo transido por la pregunta: ¿habrá una guerra europea? Todo era como un presagio de que se estaba gestando una tormenta tenebrosa. Pero no podíamos hacernos a la idea de que iba a ser una realidad. Los que han crecido en la guerra o después de la guerra no pueden ni imaginarse aquella seguridad en la que creíamos vivir hasta 1914. La paz, la tranquila posesión de los bienes, la estabilidad de las relaciones cotidianas, constituían para nosotros como un inconmovible fundamento de la vida. Cuando, finalmente, percibimos que se acercaba inexorablemente la tempestad, todos intentamos atisbar con claridad el proceso y el desenlace. Una cosa era segura: se trataba de una guerra distinta a las

36 Sobre la tesis de la potestad indirecta de la Iglesia sobre el orden temporal se puede remitir a Castaño, S. R. (2011). "El principio supremo de legitimidad de ejercicio en la tradición tomista. La teología política de Julio Meinvielle”. En Intus-Legere, 2011, vol. 5, n ${ }^{\circ}$; traducido al polaco por el Prof. Piotr Roszak y publicado en AA. VV. (2011). Katolicy i polityka. Szanse $i$ zagrozenia. Thorun, y reproducido (con revisiones) como capítulo I en Castaño, S. R. (2019). Dios y la Ciudad. Estudios de teología política. Tucumán, UNSTA. 
anteriores. Una destrucción tan horrorosa no podía durar mucho tiempo. En unos meses todo habría pasado [...].

'Ya no tengo una vida propia' [Ich habe jetzt kein eigenes Leben mehr], me dije. 'Toda mi energía está al servicio del gran acontecimiento. Cuando la guerra termine, y si entonces vivo todavía, entonces podré pensar de nuevo en mis asuntos privados' [dann darf ich wieder an meine privaten Angelegenheiten denken].

Al día siguiente, domingo, fue la declaración de guerra. Rose vino a saludarme. Por ella supe que se preparaba un curso de enfermeras para estudiantes. Inmediatamente me inscribí, y a partir de ese momento iba todos los días al Hospital de Todos los Santos [...].

Por parte de mi madre [el padre de quien escribe había fallecido] encontré una fuerte resistencia. Yo no le dije ni una palabra de que se trataba de un hospital de contagiosos. Ella sabía muy bien que no podría disuadirme con el argumento de que ponía en peligro mi vida. Por ello lo que me argumentó como medio para asustarme fue que los soldados venían del frente con la ropa llena de piojos y que de esto no tendría modo de defenderme. Realmente esto era un tormento al que yo tenía verdadero horror. Pero si los que estaban en las trincheras tenían que sufrir esto, ¿̇por qué me habría de ir mejor a mí? [...] Como estos argumentos incisivos de mi madre no surtían efecto, me dijo con toda su energía: 'no irás con mi consentimiento'. A lo cual yo repuse abiertamente: 'en ese caso, tendré que ir sin tu consentimiento"'37.

\section{Recapitulación conclusiva. Y un corolario para la doctrina social católica}

En el parágrafo III hemos señalado las consecuencias atomísticas y nominalistas que se seguían de la adopción en sede filosófica de la definición del bien común como conjunto de condiciones para el bien de la persona, y de otras similares. En el parágrafo II habíamos recordado que esta formulación errónea -errónea en la rigurosa formalidad a que están obligados los filósofos del Derecho y de la Política, y de la praxis en general- había surgido precisamente del seno de la filosofía de cuño liberal, desde donde después se extendió a otros ámbitos; y adviértase hasta qué

37 Stein, E. "Aus dem Leben einer jüdischen Familie". En Stein, E. (2000). Edith Stein Gesamtausgabe. Freiburg im Brisgau. Herder, vol. I, 181, 182, 184 y 198 (destacado nuestro). Recuperado de: https://www.karmelitinnen-koeln.de/edith-stein-archiv-kk/gesamtausgabe. Es por José Ramón Ayllón por quien conocimos este extraordinario texto; Ayllón, J. R. (1996). En torno al hombre. Madrid. Rialp: "Bien particular y bien común”, 151-153. 
punto esto enseña al filósofo su deber de contribuir en tanto filósofo al acervo sapiencial común con aquella independencia de criterio indispensable para el servicio a la verdad. Asimismo, hemos indicado cómo la noción de fin cui, en referencia al bien común político, permite poner de relieve la naturaleza humana de este bien sin por ello convertirlo en un medio del fin individual.

Nos enfrentamos, en conclusión, con una cuestión sobre la cual la razón natural posee plena competencia para expedirse, y a cuyo respecto la tradición clásica y cristiana, encabezada por Aristóteles y Tomás de Aquino, indica un camino de investigación seguro, es decir, acorde con la realidad objetiva. En este tema resultan de consulta indispensable, ante todo, dos obras ya citadas: L'humanisme politique de St. Thomas d'Aquin, de Louis Lachance, el mejor libro sobre la filosofía política de Sto. Tomás que se haya escrito; así como la más completa y rigurosa exposición del tema del bien común aparecida hasta hoy en la bibliografía mundial, Analisi del bene comune, del recientemente fallecido profesor de la LUISS, de Roma, Avelino M. Quintas, discípulo de Julio Meinvielle ${ }^{38}$.

Como el problema tratado en estas páginas, a la vez que compromete los fueros de la razón natural, reviste inocultable atingencia para la teología moral católica, estimamos pertinente concluirlas vinculando las últimas afirmaciones con el señalamiento del papel constitutivo que ostenta un recto andamiaje terminológico y conceptual en materia práctica para la Doctrina Social de la Iglesia. A propósito de lo cual resulta imperativo refrendar con Benedicto que la Doctrina Social de la Iglesia, sin perjuicio de hallarse presidida por principios dogmáticos inmutables, "argumenta desde la razón y el Derecho Natural"39.

38 En esa obra el académico argentino señala que el origen de la idea del bien común como conjunto de condiciones se halla en Rosmini. Dice el Roveretano: "Ella [la società] è conseguenza di ciò che noi abbiamo già osservato, che gli individui sono necessariamente il fine della società, e che queste non sono e non possono essere altro che de' metodi o sia de' sistemi, de' mezzi tendenti ad accrescere la felicità individuale" (Filosofia della política. Milán. Ed. D’ Addio, 1972, II parte, libro II, cap. VI, 201); citado por Quintas, A. (1988). Analisi del bene comune, 177. Asimismo, en el "Ciclo sobre temas de Política", que organizó quien esto escribe en el Instituto de Filosofía Práctica de Buenos Aires, entre septiembre y diciembre de 1996 -en el que participaron J. A. Widow, H. Hernández, R. Brie, B. Montejano, F. de Estrada, A. Padilla, E. Ventura, J. Ma Medrano, M. Lascano, E. Acevedo, F. Lamas, el director del Instituto, Guido Soaje Ramos y quien escribe-, el maestro Guido se refirió precisamente a tal genealogía doctrinal en su conferencia "El fin de la comunidad política en Sto. Tomás, en Locke y en Rosmini" (pronunciada el 4-12 de ese mismo año).

39 Benedicto XVI. Deus Caritas est, $\mathrm{n}^{\circ} 28$. 


\section{Bibliografía}

Alvira, T.; Clavell, Ll.; Melendo, T. (1982). Metafísica. Pamplona. EUNSA.

Ayllón, J. R. (1996). En torno al hombre. Madrid. Rialp.

Benedicto XVI. Caritas in veritate.

Bobbio, N. (1963). Locke e il diritto naturale. Turín. Giappichelli.

Casares, T. (1973). La justicia y el derecho. Buenos Aires. AbeledoPerrot.

Castaño, S. R. (2000). Orden político y globalización. El Estado en la contingencia actual. Buenos Aires. Ábaco de Rodolfo Depalma.

Castaño, S. R. (2005). "La politicidad natural como clave de interpretación de la historia de la filosofía política". En Sergio R. Castaño y Eduardo Soto Kloss (editores). El derecho natural en la realidad social y jurídica. Santiago de Chile. Academia de Derecho UST, 277307.

Castaño, S. R. (2005). El Estado como realidad permanente. Buenos Aires. La Ley ( $1^{\mathrm{a}}$. edición 2003).

Castaño, S. R. (2011). Los principios políticos de Sto. Tomás en entredicho. Una confrontación con Aquinas, de John Finnis. Estudio Preliminar de Camilo Tale. $2^{\text {a }}$ edición. UCALP. La Plata.

Castaño, S. R. (2011). "El principio supremo de legitimidad de ejercicio en la tradición tomista. La teología política de Julio Meinvielle”. En IntusLegere, 2011, vol. $5, \mathrm{n}^{\circ} 1$.

Castaño, S. R. (2019). Dios y la Ciudad. Estudios de teología política. Tucumán. UNSTA.

Cathrein, V. (1932). Philosophia moralis. Friburgo de Brisgovia. Herder.

Delos, J. T. (1950). La société internationale et les principes du droit public. París. Pédone.

Finnis, J. (1993). Natural Law and Natural Rights. Oxford. O. U. P.

Gonella, G. (1959). La nozione di bene comune. Milán. Giuffrè.

Guzmán, J. (1996). Derecho Político. Santiago de Chile. Ed. U. C. de Chile.

Hernández, H. H. (2000). Valor y Derecho. Buenos Aires. AbeledoPerrot.

Lachance, L. (1965). L'humanisme politique de S. Thomas d’Aquin. París-Ottawa. Éd. du Lévrier.

Locke, J. (1952). A Letter concerning Toleration (ed. Sherman). Chicago. Great Books, t. 35.

Locke, J. (1980). Second Treatise on Government. Indianapolis. Edición de C. B. Macpherson. Hackett.

Macpherson, C. B. (1989). The Political Theory of Possessive Individualism. Oxford. O.U.P.

Maritain, J. (1981). La persona y el bien común. Trad. cast. de L. de Sesma. Buenos Aires. Club de Lectores.

Medrano, J. Ma. (2005). “Tomar en serio el bien común”. En Castaño Soto Kloss. El derecho natural en la realidad social y jurídica. Santiago de Chile. Academia de Derecho UST, 4770.

Meinvielle, J. (1994). Crítica de la concepción de Maritain sobre la persona humana. Buenos Aires. Nuestro Tiempo, $1^{\mathrm{a}}$. ed. 1948. 
Pezoa, A. (1997). Política y economía en el pensamiento de John Locke. Pamplona. EUNSA.

Philippe, P. (1938). Le rôle de l'amitié dans la vie chrétienne selon S. Thomas d'Aquin. Roma. Angelicum.

Pontificio Consejo de Justicia y Paz. Compendio de Doctrina Social de la Iglesia.

Quintas, A. M. (1988). Analisi del bene comune. Roma. Bulzoni (1ª . ed. 1979).

Reyes Oribe, B. (2013). "Benedicto XVI, Defensor del Logos". En Carlos Sierra Lechuga (ed.). Estudios pontificales. México. Castilibros.

Ricci Garotti, L. (1961). Locke e i suoi problema. Urbino. U. de Urbino.

Rousseau, J. J. (1964). “Discours sur l'origine et les fondements de l'inégalité parmi les hommes”. En Oeuvres Complètes. París. Ed. de la Pléiade, T. III (Écrits politiques).

Soaje Ramos, G. (1985). "El bien común político en el Aquinate: ocho tesis". Ponencia a la Semana Tomista de 1985, pro manuscripto.

Soaje Ramos, G. (2005). "Sobre la politicidad del derecho". $1^{\text {a }}$ ed. 1958; reeditado en Castaño, S. Soto Kloss, E. (2005). El derecho natural en la realidad social y jurídica. Santiago de Chile. Academia de Derecho UST, pp. 1546.

Soto Kloss, E. (2009). Derecho administrativo. Temas fundamentales. Santiago de Chile. LexisNexis.

Stein, E. "Aus dem Leben einer jüdischen Familie". En Stein, E. (2000). Edith Stein Gesamtausgabe. Freiburg im Brisgau. Herder, vol. I.

Strauss, L. (1970). Natural Right and History. Chicago.

Tale, C. (1995). Lecciones de Filosofía del Derecho. Córdoba. Alveroni.

Tomás de Aquino. Contra impugnantes Dei cultum et religionem.

Tomás de Aquino. Summa Theologiae.

Utz, A. F. (1960). Éthique Sociale. Trad. franc. É. Dousse. Friburgo, Éd. Universitaires de Fribourg.

Widow, J. A. (1988). El hombre, animal político. Santiago de Chile. Academia de Educación.

Widow, J. L. (2004). La naturaleza política de la moral. Santiago de Chile. RIL. 